\title{
Comparative study of quality parameters of extra virgin olive oil from different regions of Khyber Pakhtunkhwa, Pakistan
}

\author{
Ata Ullah ${ }^{1 *}$, Azmat Ali Awan ${ }^{2}$, Afia Zia ${ }^{1,}$ Muhammad Muneeb ${ }^{3}$, Said \\ Badshah $^{3}$, Muhammad Younas ${ }^{4}$, Maryam Rabbi ${ }^{1}$ and Shahida Sabir ${ }^{1}$ \\ 1. Department of Agricultural Chemistry, The University Agriculture Peshawar-Pakistan \\ 2. Pakistan Oilseed Development Board Peshawar-Pakistan \\ 3. Department of food science and technology, The University Agriculture Peshawar-Pakistan \\ 4. Department of Environmental science, International Islamic University, Islamabad-Pakistan \\ *Corresponding author's email: hamdard4naz@yahoo.com, attabjr821@gmail.com \\ Citation
}

Ata Ullah, Azmat Ali Awan, Afia Zia, Muhammad Muneeb, Said Badshah, Muhammad Younas, Maryam Rabbi and Shahida Sabir. Comparative study of quality parameters of extra virgin olive oil from different regions of Khyber Pakhtunkhwa, Pakistan. Pure and Applied Biology. Vol. 7, Issue 1, pp263-270.

http://dx.doi.org/10.19045/bspab.2018.70032

Received: 21/11/2017 Revised: 08/02/2018

Accepted: $10 / 02 / 2018$

Online First: 16/02/2018

\section{Abstract}

The purpose of this study was to evaluate the physical and chemical characteristics of Pendallino olive cultivar oils from from the various cities of Khyber Pakhtunkhwa to identify and compare the oils with international standard defined by Olive Oil Council (IOOC) for Virgin olive oil. The olive fruits were taken from the specific regions of Khyber Pakhtunkhwa i.e. Bajaur, Karak, Lower Dir and Peshawar. Virgin olive Oils (VOO) were extracted by pressing and centrifuging of olive fruits with three-phase vertical decanter. The extracted virgin olive oil was studied for various physiochemical properties and fatty acid profile. The Physical and chemical properties i.e., acidity, peroxide, ultraviolet spectrophotometric analysis (k232 and k270), total phenol content, chlorophyll pigment were under the acceptable range, established by European regulation for virgin olive oil. Olive oil was analyzed by GC gas-chromatography for fatty acids commonly present in olive oils which are: palmitic, palmitoleic, stearic, oleic, linoleic, linolenic, and arachidic. Oleic acid was found in high percentage ranged from (60.3 to $74.3 \%$ ), followed by linoleic, palmitic, stearic, palmitoleic and linolenic. Arachidic acid was found in a very low percentage in all olive oil samples. Total phenol contents ware ranged from 114 to $125 \mathrm{mg} / \mathrm{kg}$. The International Olive Oil Council's (IOOC) criteria for pureness and excellence was used as a standard for the calculated values of the samples. The samples had significant physical and chemical properties and can be used as edible oil. The Lower Dir cultivar particularly demonstrated the qualities of a superior of olive oil.

Keywords: Chlorophyll; Fatty acid profile; Total phenol contents; Virgin olive oil

Introduction

Virgin olive oil (VOO) is considered a tremendous natural food throughout the world. VOO is fruit attained from olive plant (Olea europaea, $L$ ) by physical or automated actions. Beating, centrifugation, milling, and 
decantation are mechanical or physical procedure used for the extraction of $\mathrm{VOO}$ from the olive fruits [1].

Fruit variety, growing region, degree of fruit ripening, ecological situations and methods of processing and storage are directly related to the composition of olive oil. Color is one of the key quality characteristics of virgin olive oil (VOO). Olive oil color is influenced by these factors $[2,3]$.

Virgin olive oil is defined by International standards the oil that obtained from olives, by physical or other mechanical methods that do not alter the composition of the oil. This process is specifically performed by excluding heating and chemical processing. Extra Virgin olive oils (EVOO) are the best quality of virgin olive oil. It must meet the analytical criteria of IOOC and will be free of any physiochemical defects and it is known that the quality of virgin olive oils, which have all regarding product, nutritional and technological features and composition and the concentration of the antioxidants [4].

Peroxide value, total phenol contents, free fatty acid, spectrophotometric indices at wavelength 232 and $270 \mathrm{~nm}$, namely K232 and K270 and fatty acid profile are the different quality characteristics for the virgin olive oils [5].

During extraction, processing, and storage free fatty acid are formed due the hydrolysis of triacylglycerol. When oils are exposed to oxygen peroxide are formed which is the primary oxidation product. Peroxide produces undesirable flavors and odors. UV absorption specific is used for conjugated double bonds formed from natural oils. No conjugated unsaturation found in oils upon oxidation. The human body assimilates the olive oil. High percentage of triolein is responsible for the assimilation of the oil in human body. Chlorophyll pigments, aroma components and pheophytin facilitate the absorption of olive oil from the body [6].
High mono-unsaturation of olive oil, phenols, sterol, squalene, aroma and tocopherols, chlorophyll and pheophytin and flavor compounds and others play important role on the health of human body. Highly monounsaturated olive oil, show is resistant to oxidation [7].

Oxidation in the body leads to the free radicals which are responsible serious problem on human health. Vitamin-E and phenols act as free radicals scavengers for the protection of free radicals. Olive oil, possess the significant amount of these molecules to prevent the human's cell destruction. Antiinflammatory, antithrombotic antiatherogenic, , anticarcinogenic, immune modulating and analgesic activities are due to the secondary metabolites, which are derived from polyphenol and work as antioxidants in our body [8].

VOO possess a lot of polyphenols such as ester of hydroxytyrosol and tyrosol and hydroxytyrosol. They having acidic properties that's why extra virgin olive oil have nasty and sharp taste. EVOO consist more than 30 phenolic compounds. Flavonoids and lignans (acetoxypinoresinol, pinoresinol) are also present in Olive oil. The lignans and flavonoids (pinoresinol, acetoxypinoresinol) are the only compounds present in extra virgin oil. Natural pigments (chlorophylls, pheophytin, and carotene) have also a key role in the constancy and technological characteristics of olive oil [9].

The purpose of the current study was to appraise the physiochemical properties, total phenol contents and fatty acid structure of olive oils from four different cities (Bajur, Karak, Lower Dir and Peshawar) of the Khyber Pakhtunkhwa olive varieties. Another aim of the study is determine health protecting components and all other quality parameter of the olive varieties of four different regions. 
For purity and quality criteria of olive oil, the samples were compared with International Olive Oil Council, (IOOC).

\section{Materials and methods \\ Samples}

The samples of Pendallino olive cultivar were received from the farmers in (October 2016), from different location of Khyber Pakhtunkhwa such as Bajaur, Karak, Lower Dir and Peshawar. The olive fruits were transferred to Pakistan Council and industrial research (PCSIR) labs for the analysis of physicochemical properties, total phenol and fatty acid profile. The oil was extracted from olive fruits through mechanical procedure. The extracted oil was stored into sterilized bottles.

\section{Quality parameters}

EC 2568/91 regulation [10] method was used for evaluation of the peroxide value - PV, free fatty acid - FFA, K232 and K270.

\section{Total Phenolic contents}

The $10 \mathrm{~g}$ of oil was disbanded in $50 \mathrm{ml}$ hexane. The $3 \times 20 \mathrm{ml}$ parts of aqueous methanol $60 \%$ were used for the extraction of solution. The mixture was shaken for two minutes and the united extracts were dried in a vacuum rotary evaporator for 2 minutes. The remaining residue has been dissolved in $1 \mathrm{ml}$ methanol. The samples were stored at $20^{\circ} \mathrm{C}$ until it was used. Folin-Ciocalteu reagent was used for the total polyphenol content of the methanol extracts evaluation calorimetrically [11]. Standard phenolic was mixed with Folin- Ciocalteau reagent $(5 \mathrm{ml}$ diluted with Nanopure water, 1:10) and 4ml aqueous, $1 \mathrm{M} \mathrm{Na} 2 \mathrm{CO} 3$, and the Solutions were sustained for 60 minutes at room temperature and the total polyphenols were resolute calorimetrically at $725 \mathrm{~nm}$.

\section{Analysis of fatty acids}

European Community Regulation (Commission Regulation) [12] was used for the analysis of fatty acids. Methanol solution of $2 \mathrm{~N} \mathrm{KOH}$ was used for the esterification of the olive oil sample for 30 minutes at $500 \mathrm{C}$.
The gas-chromatographic investigates of fatty acid methyl esters were done on a Perkin Elmer gas chromatograph. The diameter 0.25 $\mu \mathrm{m}$ column was a fused silica Helium was used as carrier of gas $(6 \mathrm{~mL} / \mathrm{min})$. The temperature of the column was initially kept at $1400 \mathrm{C}$ for $10 \mathrm{~min}$. Early programed rate of $10 \mathrm{C} / \mathrm{min}$, up to $1600 \mathrm{C}$. The 2 nd rate was $20 \mathrm{C} / \mathrm{min}$ upto $2200 \mathrm{C}$ and a final isotherm for $15 \mathrm{~min} .1^{\text {st }}$ Samples were inserted into the split mode the gadget automatically and carried out recording and integration. The gas-chromatographic peaks were recognized as matching fatty acid.

\section{Pigments}

Pigments were taken out from the virgin olive oil samples and the total Chlorophylls contents of the olive oil were examined with spectrophotometric technique with the procedure suggested by [13].

$\mathrm{Mg} / \mathrm{kg}$ is used for the expression of chlorophyll content in olive oil. The liquid sample was homogenized. The liquid samples were filtered immediately by using a medium-pore size filter paper. The absorbance for the samples was recorded by at $630 \mathrm{~nm}, 670 \mathrm{~nm}$ and $710 \mathrm{~nm}$ wavelength in a $10 \mathrm{~mm}$ spectrophotometer.

Formula for the content of chlorophyll pigments:

$\mathrm{C}=345.3 \times(\mathrm{A} 670-.5 \times \mathrm{A} 630-.5 \times \mathrm{A} 710) /$ L.

Where: $\mathrm{C}=$ Represent the chlorophyll content pigments in milligrams of pheophytin a in $1 \mathrm{~kg}$ of oil,

$\mathrm{A}=$ absorbance at the $(\mathrm{nm})$ respective wavelength.

$\mathrm{L}=$ Spectrophotometer cell thickness (mm).

\section{Results and disscusion}

Quality parameters

All the Results for quality parameters for all the EVOO samples within the limits fixed by IOOC irrespective of the origin of oil. All the results (peroxide value $\mathrm{PV}$, free fatty acid FFA, K232 and K270) are inserted in table 1. 
Table 1. Estimative mean values for quality parameters of different analyzed olive oil

\begin{tabular}{|c|c|c|c|c|c|}
\hline Type of oil & Sample Nr. & PV & FFA & K232 & K270 \\
\hline & Limit & $\leq 20 \mathrm{mEqO} 2 / \mathrm{kg}$ Oil & $0.8 \%$ ac.oleic & $\leq 2.5$ & $\leq 0.22$ \\
\hline \multirow{4}{*}{$\begin{array}{c}\text { EVOO Bajaur } \\
\text { Agency }\end{array}$} & B1 & 10.50 & 0.13 & 1.23 & 0.14 \\
\hline & $\mathrm{B} 2$ & 9.69 & 0.14 & 1.21 & 0.13 \\
\hline & B3 & 12.5 & 0.1 & 1.15 & 0.11 \\
\hline & Mean \pm sd & $11.52 \pm 0.86$ & $0.11 \pm 0.015$ & $1.21 \pm 0.06$ & $0.12 \pm 0.015$ \\
\hline \multirow{4}{*}{ EVOO Karak } & K1 & 13.5 & 0.12 & 1.75 & 0.16 \\
\hline & $\mathrm{K} 2$ & 11.4 & 0.13 & 1.66 & 0.15 \\
\hline & K3 & 12.9 & 0.11 & 1.8 & 0.17 \\
\hline & Mean \pm sd & $12.56 \pm 0.97$ & $0.10 \pm 0.015$ & $1.73 \pm 0.06$ & $0.16 \pm 0.01$ \\
\hline \multirow{4}{*}{$\begin{array}{c}\text { EVOO } \\
\text { Peshawar }\end{array}$} & $\mathrm{P} 1$ & 7.5 & 0.14 & 2.1 & 0.21 \\
\hline & $\mathrm{P} 2$ & 8.4 & 0.11 & 2.09 & 0.19 \\
\hline & P3 & 7.3 & 0.13 & 2.23 & 0.2 \\
\hline & Mean $\pm \mathrm{sd}$ & $7.9 \pm 0.4$ & $0.12 \pm 0.015$ & $2.13 \pm 0.07$ & $0.2 \pm 0.01$ \\
\hline \multirow{4}{*}{ Lower Dir } & L1 & 12.8 & 0.14 & 1.23 & 0.23 \\
\hline & L2 & 11.7 & 0.15 & 1.16 & 0.25 \\
\hline & L3 & 14 & 0.14 & 1.24 & 0.18 \\
\hline & Mean \pm sd & $12.56 \pm 0.97$ & $0.11 \pm 0.015$ & $1.21 \pm 0.06$ & $0.2 \pm 0.01$ \\
\hline
\end{tabular}

\section{Total phenol contents}

The Results for the total phenolic content are shown in figure 1, and it shows that the extra virgin olive oil contains polyphenol contents. The polyphenol contents depends on their botanical variety, the region where the olives are harvested and Environmental conditions
[14]. Evaluating our results, the four analyzed samples are good source of polyphenol contents (between 114-125 mg of Gallic acid equivalents/ $1 \mathrm{~kg}$ oil). The result were quit Similar to the results obtained by $[15,17]$.

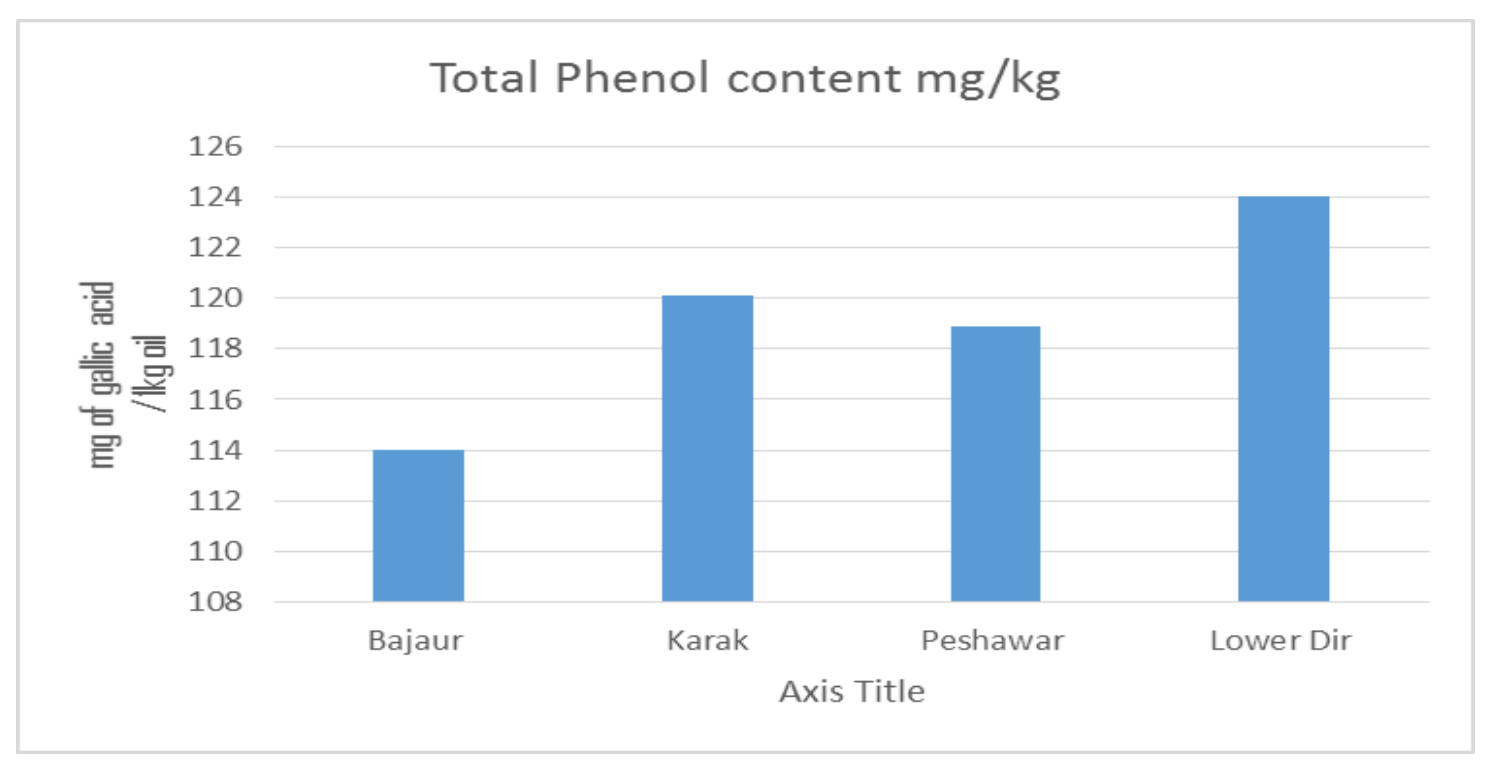

Figure 1. Total phenolic compound content of the olive oil samples 


\section{Fatty acid composition of olive oils samples}

The qualitative assessment of olive oil is directly associated to the configuration of the fatty acid. The nutritional implications and oxidative stability of oils are related to the unsaturated fatty acid (UFA). The four samples were examined by gas chromatography for fatty acid compositions and the result are inserted in table 2.

Table 2. Profile of Fatty acid profile of the four olive oils samples

\begin{tabular}{|l|l|l|c|c|c|l|l|}
\hline Sample & $\begin{array}{l}\text { Palmitic } \\
\text { acid }\end{array}$ & $\begin{array}{l}\text { Palmitoleic } \\
\text { Acid }\end{array}$ & $\begin{array}{c}\text { Linoleic } \\
\text { acid }\end{array}$ & $\begin{array}{c}\text { Oleic } \\
\text { acid }\end{array}$ & $\begin{array}{c}\text { Linolenic } \\
\text { acid }\end{array}$ & $\begin{array}{l}\text { Stearic } \\
\text { acid }\end{array}$ & $\begin{array}{l}\text { Arachidic } \\
\text { acid }\end{array}$ \\
\hline Bajaur & 8.99 & 1.47 & 16.5 & 60.3 & 1.03 & 2.24 & 0.14 \\
\hline Karak & 6.5 & 0.94 & 10.2 & 71.5 & 0.61 & 3.31 & 056 \\
\hline LowerDir & 7.771 & 1.04 & 12.3 & 67.5 & 0.88 & 2.65 & 0.13 \\
\hline Peshawar & 5.55 & 0.35 & 7.07 & 74.3 & 0.34 & 3.33 & 0.46 \\
\hline
\end{tabular}

By examination the fatty acid configuration, differences between the four samples were witnessed. Oleic acid was present in highest concentration it is clear that from the fig 2 that concentration of oleic acid was present in the highest amount; the values were oscillated between $59.3 \%$ and $77.3 \%$ (Figure 2).

\section{PERCENTAGE OF OLEIC ACID}

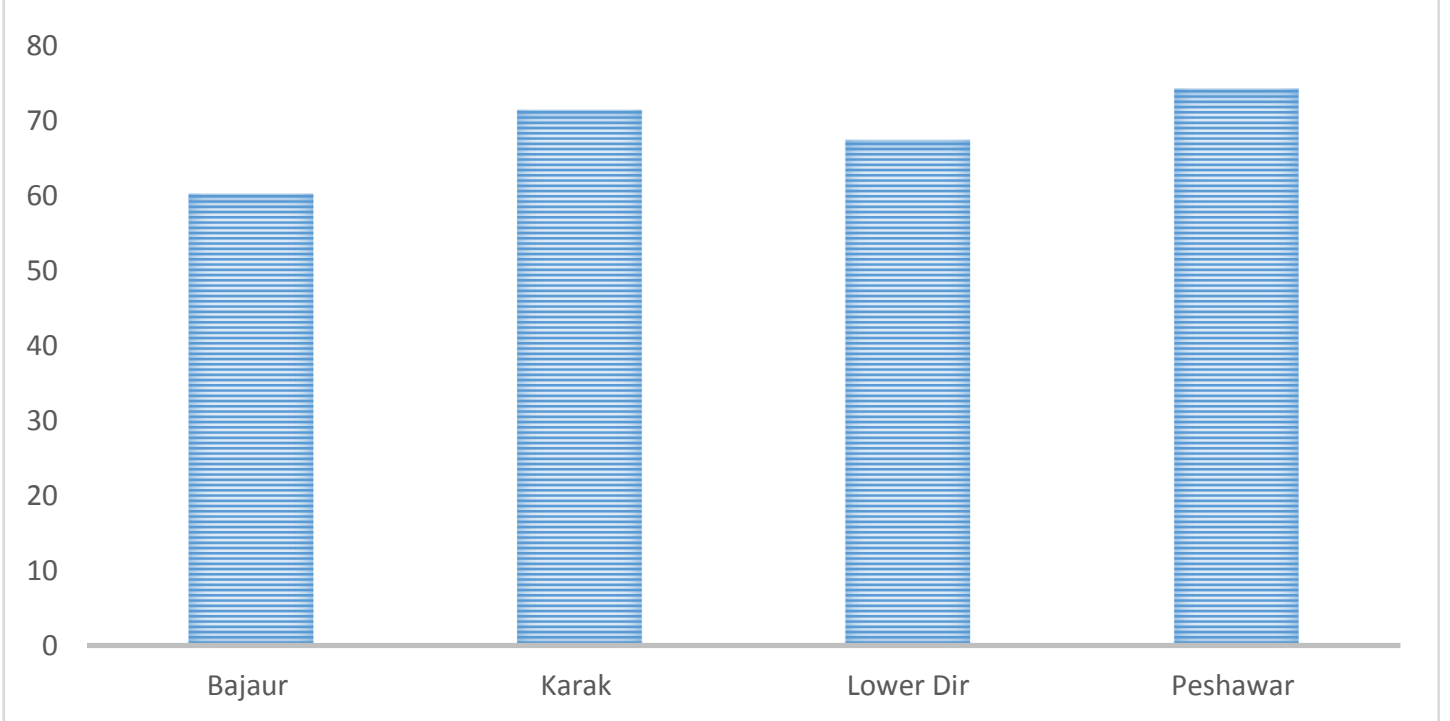

Figure 2. Percetage of olic acid

It was followed by linoleic acid (7.07 $16.5 \%)$, palmitic acid (5.5 - 8.99\%), stearic acid $(2.24-3.33 \%)$. The linolenic acid $(0.34$ $-1.02 \%)$ and palmitoleic acid (0.34 - 1.47\%) were present at less amount in the analyzed sample. Oleic acid (77.3\%) were present at highest concentration in the sample of
Peshawar but sample taken from Bajaur possess lowermost percentage of the same fatty acid (59.3\%). Species, genetics, variety, climatic condition, growing conditions, locality, and postharvest handling may be responsible for the variation among the results of the analyzed samples $[9,18]$. 


\section{Chlorophyll content}

It is clear from recent literature that the chlorophylls contribute to the evaluation of the intrinsic the authenticity, quality and the geographical origin of EVOO [20]. Results of the determination of chlorophyll pigments content are included in (Figure 3).
By evaluating the chlorophyll contents of four different olive oil samples a very small difference among the samples were witnessed regarding the chlorophyll contents. The highest concentrations was found in Lower 23.17 and lowest at Peshawar sample $19.06 \mathrm{a} / \mathrm{kg}$ oil.

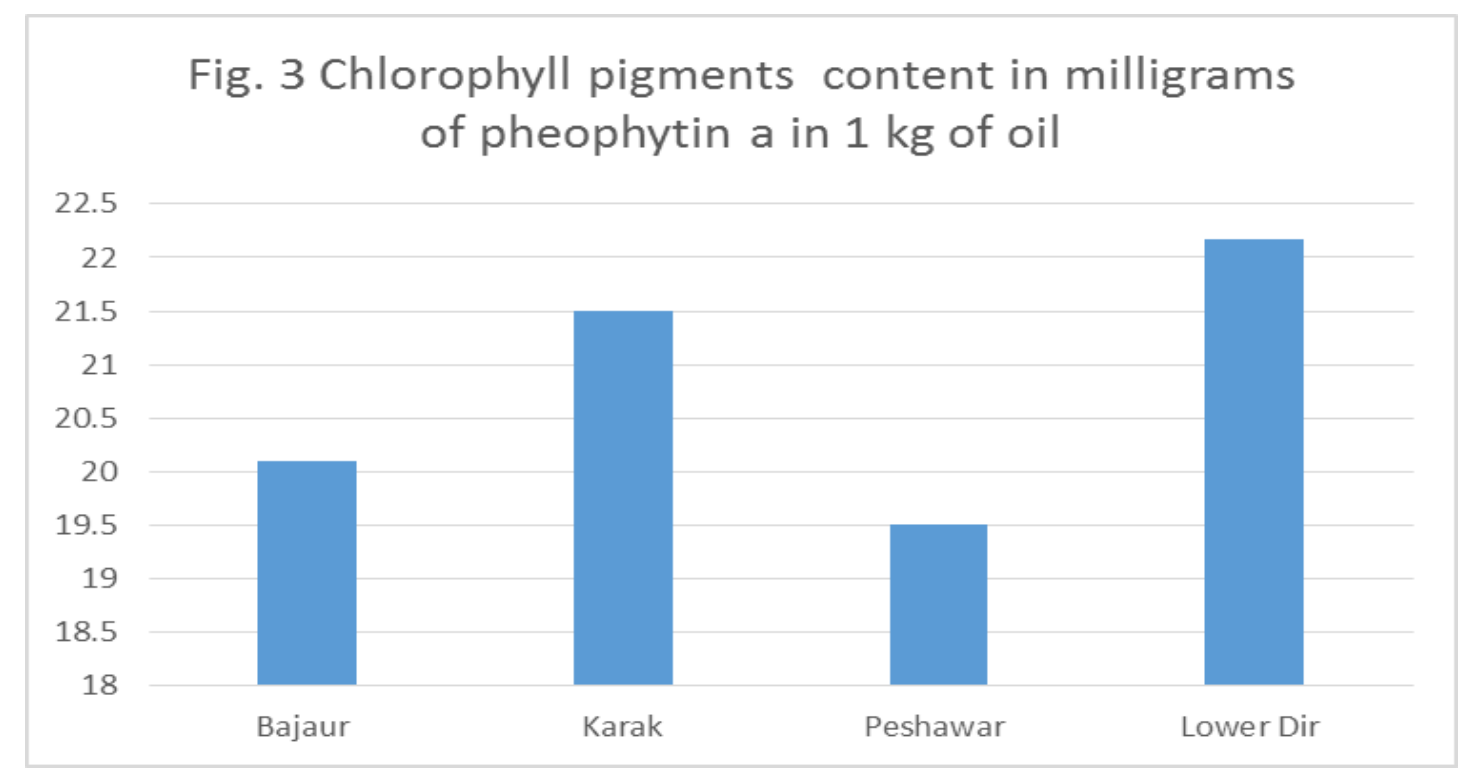

Figure 3. Chlorophyll pigments content in milligrams of pheophytin an in $1 \mathrm{~kg}$ of oil

\section{Conclusions}

The main focus of this performed research was to appraise the purity and quality of Virgin olive oils. The study was based on the international standards and to deliver a quality product for customers. Due to suitability of the climatic conditions and quality of inborn cultivars Pakistan has great potential for the olive cultivation.

The analyzed results of the samples from four different cities of the Khyber Pakhtunkhwa olive varieties showed that the varieties are free from any flaws and the results were within the limits fixed by IOOC. According to international olive oils council these samples were classified as virgin olive oil. Peroxides and Acidity values were according to standard limits for virgin olive oil, although small differences among the physiochemical properties of olive oils samples are exist. The samples have good properties of low percentage of acidity.

Phenolic compounds have strong antioxidant activity; inhibit lipid oxidation, which are responsible beneficial effect in human body and the stability of oil. Among the four analyzed samples the Lower Dir olive oil has the highest content of chlorophyll and antioxidant. The analyzed from different region of the Khyber Pakhtunkhwa can be used as source of eatable oil for human food.

\section{Authors' contributions}

Conceived and designed the experiments: A Ullah \& AA Awan, Performed the experiments: A Ullah \& M Muneeb, Analyzed the data: A Ullah \& A Zia, 
Contributed materials/ analysis/ tools: S Badshah, M Rabbi \& S Sabir, Wrote the paper: A Ullah, M Muneeb \& S Badshah.

\section{References}

1. Gandul, BR, Cepero MRL \& Mínguez, MMI (2000). Use of chlorophyll and carotenoid pigment composition to determine authenticity of virgin olive oil. Journal of the American Oil Chemists' Society 77(8): 853-858.

2. Fernandez-Escobar R, Benlloch $M$, Barranco D, Duenas A \& Gañán J G (1996). Response of olive trees to foliar application of humic substances extracted from leonardite. Scientia Horticulturae 66(3-4): 191-200.

3. Gutiérrez-Rosales F, Garrido-Fernández J, Gallardo-Guerrero L, Gandul-Rojas B \& Minguez-Mosquera, MI (1992). Action of chlorophylls on the stability of virgin olive oil. Journal of the American Oil Chemists Society 69(9): 866-871.

4. Del Carlo M, Ritelli E, Procida G, Murmura F \& Cichelli A (2006). Characterization of extra virgin olive oils obtained from different cultivars. Pomologia Croatica 12(1): 29-41.

5. Aman MM, Basuny, Arafat MS, Dalia MM \& Mostfa (2008). Virgin olive oil quality: relationship between bioactive components and organoleptic evaluation.Alex. J.Fd.Sc. \& Techn. Special Volume of Conference pp: 22-29.

6. Kiritsakis AK (2013). Composition of olive oil and its health effects. Internet: http://www. Olive business. Com/OBGuest/Kirit/composition of olive oil and its. htm (Accessed 5 August 2005).

7. Iconomou D, Arapoglou D \& Israilides C (2010). Improvement of phenolic antioxidants and quality characteristics of virgin olive oil with the addition of enzymes and nitrogen during olive paste processing. Grasas y Aceites 61(3): 303311.
8. Gómez-Caravaca AM, Gómez-Romero M, Arráez-Román D, Segura-Carretero A \& Fernández-Gutiérrez A (2006). Advances in the analysis of phenolic compounds in products derived from bees. Journal of Pharmaceutical and Biomedical Analysis 41(4): 1220-1234.

9. Capella P, Fedeli E, Bonaga G \& Lercker G (1991). Manuale degli oli e grassi. EC 2568/91 regulation (EC, 1991).

10. Singleton VL Rossi J A (1965). Colorimetry of total phenolics with phosphomolybdic-phosphotungstic acid reagents. American journal of Enology and Viticulture 16(3): 144-158.

11. Regulation H (1991). Commission Regulation (EEC) No. 2568/91 of 11 July 1991 on the characteristics of olive oil and olive-residue oil and on the relevant methods of analysis Official Journal L 248, 5 September 1991. Off J L 248: 1-83.

12. Minguez-Mosquera MI, Gandul-Rojas B, Garrido-Fernandez J GallardoGuerrero L. (1990) Pigments present in virgin olive oil. Journal of the American Oil Chemists' Society 67(3):192-196.

13. Pokorny J, Kalinova L \& Dysseler P (1995). Determination of chlorophyll pigments in crude vegetable oils: Results of a collaborative study and the standardized method (Technical Report). Pure and Applied Chemistry 67(10): 1781-1787.

14. Baiano A, Gambacorta G, Terracone C, Previtali MA, Lamacchia C La Notte E (2009). Changes in Phenolic Content and Antioxidant Activity of Italian ExtraVirgin Olive Oils during Storage. Journal of food science 74(2).

15. Del Carlo M, Ritelli E, Procida G, Murmura F Cichelli A (2006). Characterization of extra virgin olive oils obtained from different cultivars. Pomologia Croatica 12(1): 29-41. 
16. Inarejos-García AM, Santacatterina M, Salvador MD, Fregapane G GómezAlonso S (2010). PDO virgin olive oil quality-Minor components and organoleptic evaluation. Food Research International 43(8): 2138-2146.

17. Patumi M, Andria R, Marsilio V, Fontanazza G, Morelli G \& Lanza B (2002). Olive and olive oil quality after intensive monocone olive growing (Olea europaea L., cv. Kalamata) in different irrigation regimes. Food Chemistry, 77(1): 27-34.

18. Regulation H (1991). Commission Regulation (EEC) No. 2568/91 of 11 July 1991 on the characteristics of olive oil and olive-residue oil and on the relevant methods of analysis Official Journal L 248, 5 September 1991. Off $J$ L 248: 1-83.

19. Cerretani L, Motilva MJ, Romero MP, Bendini A \& Lercker G. (2008) Pigment profile and chromatic parameters of monovarietal virgin olive oils from different Italian cultivars. European Food Research and Technology 226(6): 1251-1258.

20. Aparicio-Ruiz, R, Gandul-Rojas B \& Roca M (2009). Pigment profile in nonSpanish olive varieties (Olea europaea L. Var. Coratina, Frantoio, and Koroneiki). Journal of agricultural and food chemistry 57(22): 10831-10836. 